\title{
Early outcome of acute peripartum cardiomyopathy in eastern part of Nepal
}

\author{
Rajesh Nepal, ${ }^{1}$ Madhav Bista, ${ }^{1}$ Sita Ghimire ${ }^{2}$
}

${ }^{1}$ Cardiology unit, department of internal medicine, Nobel Medical College, Biratnagar, Nepal
${ }^{2}$ Department of gynecology and obstetrics, Nobel Medical College, Biratnagar, Nepal

Corresponding Author: Rajesh Nepal

Cardiology unit, Department of internal medicine,

Nobel Medical College, Biratnagar, Nepal,

Email Address: rajesh328@hotmail.com

\begin{abstract}
Background and Aims: Peripartum cardiomyopathy (PPCM) is an uncommon complication of pregnancy with variable outcome. There is paucity of data related to its outcomes in Nepal.We studied the clinical and echocardiographic outcome of PPCM patients in eastern part of Nepal.

Methods: : In this prospectively designed study all patients admitted with the diagnosis of acute severe PPCM at Nobel Medical College, Biratnagar, meeting the inclusion criteria over a period of 14 month, were enrolled and followed up for 3 months post partum. The LVEF and Left ventricular end diastolic dimension (LVEDD) was assessed by echocardiography at baseline and 3 months postpartum.Mortality and survival with normal or depressed ejection fraction were determined. Predictors of outcome were evaluated. Statistical analysis were done using SPSS version 17. Results: Mean age of the study population was $27.6 \pm 5.6$ years. Ninety five percent of patient had term delivery.Sixty four percent were primigravida.Eighty four percent had the symptoms onset in post partum period.Pulmonary edema was present in $64 \%$ during first hospital admission. Mortality was $9 \%$ during 3 -month follow up period. Thirty six percent had complete recovery of LVEF at 3 months. Fifty five percent survived with depressed LVEF. Age, LVEF less than $30 \%$ and LVEDD more than $60 \mathrm{~mm}$ at study entry did not correlate significantly with poor clinical recovery at 3 months.

Conclusion: This study demonstrates that survival outcome is better even in the patients with severe acute PPCM with early diagnosis and proper management of heart failure.
\end{abstract}

Keywords : : Left ventricular ejection fraction, Mortality outcome, Peripartum cardiomyopathy

\section{Background}

Peripartum cardiomyopathy (PPCM) is a rare complication of pregnancy but remains a major cause of maternal morbidity and mortality. ${ }^{1}$ The clinical presentation is similar to that of other forms of cardiomyopathy with onset in the later part of pregnancy or first few months post-partum. ${ }^{2}$ Outcomes of PPCM are markedly variable ranging from complete recovery to surviving with heart failure or death. ${ }^{3}$ Low left ventricular ejection fraction (LVEF) less than 30 percent and left ventricular end diastolic diameter (LVEDD) more than $60 \mathrm{~mm}$ were shown to have worse prognosis. ${ }^{4}$ Given the low prevalence of the disorder, most single center reports are limited in study number and being retrospective. There are minimal prospective data on clinical outcomes of contemporary evidence based therapy., ${ }^{5,6}$ In Nepal there are sparse studies to evaluate the outcome of severe acute PPCM. We attempted to evaluate the mortality and survival with depressed/ normal ejection fraction and predictors of these outcomes.

\section{Method}

This prospective observational study was carried out at cardiology unit of department of medicine at Nobel Medical College, Biratnagar over a period of fourteen months from
July 2015 to September 2016. All consecutive PPCM patients admitted for management of acute heart failure were enrolled in the study. Ethical clearance was taken from the institutional review board of Nobel medical college. Written informed consent was taken from the patient or her relative.

Inclusion criteria included

a. PPCM patients admitted for management of heart failure.

b. Age more than 18 years.

PPCM was defined as estimated LV ejection fraction of less than $45 \%$ with no other obvious cause of LV dysfunction in the last month of pregnancy or 5 moths post partum.

Exclusion criteria included

a. Past history of PPCM,

b. Valvular heart disease,

c. Coronary artery disease,

d. Severe sepsis,

e. Alcohol abuse and

f. Chemotherapy

g. Chest radiation.

Demographic, clinical and echocardiographic parameters were recorded at the time of enrollment. LVEF was calculated by eyeballing method. LVEDD was taken in parasternal long 
axis view. Clinical evaluation and echocardiography was done at first contact in all patients and 3 months in surviving patients. Complete recovery was defined as LVEF more than $50 \%$ and recovery with depressed ejection fraction was defined as ejection fraction less than $50 \%$. All patients received the guideline recommended standard medical treatment for heart failure wherever applicable. The primary end point was the 3 -month outcome (mortality verses survival with normal or depressed ejection fraction). The secondary end point was correlation of LVEF, LVEDD and age with the primary outcome.

\section{Statistical analysis:}

Descriptive analysis with mean \pm standard deviation $(\mathrm{SD})$ was calculated for numerical variables. Frequencies with percentages were given for categorical variables. Chi square test was applied to find the significant correlation between the variables and outcome by using SPSS version 17 .

\section{Result}

A total of 22 women were included in the study. Mean age of the study population was 27.6 \pm 5.6 years (range 20-40). During the 3-month follow up postpartum, 2 (9\%) women died. Eight $(36.4 \%)$ women survived with full recovery and $12(54.6 \%)$ were surviving with depressed ejection fraction as shown in Fig1.

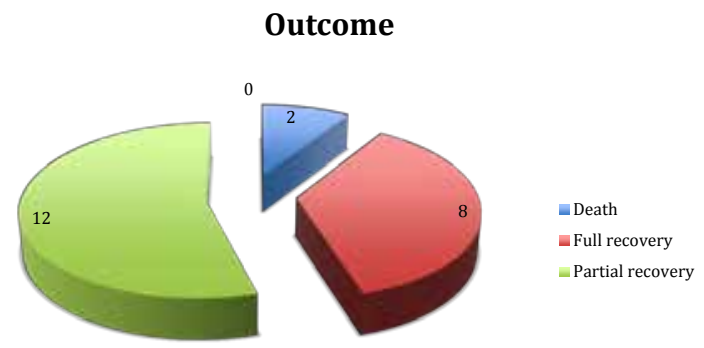

Fig 1. Outcomes of the patients.

Fourteen $(63.6 \%)$ women were primigravida with a mean parity of $1.68 \pm 0.56$. Nineteen $(86 \%)$ women had symptom onset in postpartum period. Sixty four percent had vaginal delivery while $36 \%$ underwent lower segment cesarean section. Sixty four percent of the women had pulmonary edema at the time of admission. Nine percent women had twin delivery. Mean duration of follow up was 191 (5-380 days). All surviving women were followed up for more than 3 month as shown in Table 1 .

\begin{tabular}{|l|l|}
\multicolumn{2}{|c|}{ Table 1. Clinical characteristics of the patients } \\
\hline \multicolumn{1}{|c|}{ Parameters } & \multicolumn{1}{|c|}{ Values } \\
\hline Mean age (years) & $27.6 \pm 5.6(20-40)$ \\
\hline Symptom onset before delivery & $3(13.6 \%)$ \\
\hline Symptom onset after delivery & $19(86.4 \%)$ \\
\hline Preterm delivery & $1(4.5 \%)$ \\
\hline Term delivery & $21(95.5 \%)$ \\
\hline Pulmonary edema at presentation & $14(63.6 \%)$ \\
\hline Vaginal delivery & $14(63.6 \%)$ \\
\hline LSCS & $8(36.4 \%)$ \\
\hline Primigravida & $14(63.6 \%)$ \\
\hline Mean parity & $1.68 \pm(1-6)$ \\
\hline
\end{tabular}

Mean LVEF at study entry was 26.82 (15-45\%). Sixty four percent had LVEF less than $30 \%$ at the study entry while $36 \%$ had more than 30\%LVEF. Mean LVEF at 3-month follow up was $39.31 \%$ with the mean increment by12.5. Mean LVEDD at study entry was $52.9(44-70 \mathrm{~mm})$, which decreased by a mean of $4.3 \mathrm{~mm}$ during follow up as shown in Table 2 .

Table 2. Echocardiographic parameters

\begin{tabular}{|l|l|}
\hline Mean LVEF at study entry & $26.82 \pm 8.38(15-45 \%)$ \\
\hline Mean LVEF at 3 month & $39.31 \pm 12.8(14-55 \%)$ \\
\hline LVEF $<30 \%$ at study entry & $14(63.6 \%)$ \\
\hline LVEF $>30 \%$ at study entry & $8(36.4 \%)$ \\
\hline Mean LVEDD at study entry & $52.9 \pm 6.8(44-70 \mathrm{~mm})$ \\
\hline Mean LVEDD at 3 month & $48.63 \pm(39-64 \mathrm{~mm})$ \\
\hline LVEDD $<60$ mm at study entry & $19(86.4 \%)$ \\
\hline LVEDD $>60$ mm at study entry & $3(13.6 \%)$ \\
\hline
\end{tabular}

Of the 2 patients who did not survive, both had LVEF $<30 \%$ at the time of presentation and LVEDD also less than $60 \mathrm{~mm}$ as shown in Table3.

\begin{tabular}{|l|l|l|l|l|l|}
\hline \multicolumn{5}{|c|}{ Table 3. Echocardiographic parameter and clinical outcome. } \\
\hline \multirow{2}{*}{} & & Death & $\begin{array}{l}\text { Full } \\
\text { recovery }\end{array}$ & $\begin{array}{l}\text { Partial } \\
\text { recovery }\end{array}$ & Total \\
\hline \multirow{2}{*}{$\begin{array}{l}\text { LVEF } \\
\text { at study } \\
\text { entry }\end{array}$} & $<30 \%$ & $2(14.3 \%)$ & $7(50 \%)$ & $5(35.7 \%)$ & $14(100 \%)$ \\
\cline { 2 - 7 } Total & $>30 \%$ & 0 & $5(22.7 \%)$ & $3(37.5 \%)$ & $8(100 \%)$ \\
\hline $\begin{array}{l}\text { LVEDD } \\
\text { at study } \\
\text { entry }\end{array}$ & $>60 \mathrm{~mm}$ & $2(10.5 \%)$ & $10(52.6 \%)$ & $7(36.8 \%)$ & $19100 \%$ \\
\hline Total & 0 & $2(66.7 \%)$ & $1(33.3 \%)$ & $3(100 \%)$ \\
\hline
\end{tabular}

LVEF less than or more than $30 \%$ at the study entry, LVEDD less than or more than $60 \mathrm{~mm}$ and age more than or less than 25 years were correlated with the myocardial recovery but none of them were found to have significant association. ( $p$ value: $0.91,0.15,0.86$ respectively).

\begin{tabular}{|c|c|c|c|}
\hline & $\begin{array}{l}\text { Full recovery } \\
(\text { LVEF }>50 \%)\end{array}$ & $\begin{array}{l}\text { Partial recovery } \\
(\mathrm{LVEF}<50 \%)\end{array}$ & $\begin{array}{c}\mathrm{P} \\
\text { value }\end{array}$ \\
\hline LVEF at study entry $<30 \%$ & $9(64.3 \%)$ & $5(35.7 \%)$ & \multirow{3}{*}{0.91} \\
\hline LVEF at study entry $>30 \%$ & $5(62.5 \%)$ & $3(21.5 \%)$ & \\
\hline Total & $14(63.6 \%)$ & $8(36.4 \%)$ & \\
\hline $\begin{array}{l}\text { LVEDD at study entry } \\
<60 \mathrm{~mm}\end{array}$ & $12(63.2 \%)$ & $7(36.8 \%)$ & \multirow{3}{*}{0.15} \\
\hline $\begin{array}{l}\text { LVEDD at study entry } \\
>60 \mathrm{~mm}\end{array}$ & $2(66.6 \%)$ & $1(33.3 \%)$ & \\
\hline Total & $14(63.6 \%)$ & $8(36.4 \%)$ & \\
\hline Age $<25$ years & $6(66.6 \%)$ & $3(33.3 \%)$ & \multirow{3}{*}{0.86} \\
\hline Age $>25$ years & $8(61.5 \%)$ & $5(38.5 \%)$ & \\
\hline Total & $14(63.6 \%)$ & $8(36.4 \%)$ & \\
\hline
\end{tabular}




\section{Discussion}

In this prospectively designed study twenty-two women with PPCM were enrolled and treated with standard heart failure medical management. Though all patients were in severe heart failure, majority (91\%) had clinical recovery. Nine percent of the patient died during the follow up. This result is similar to the findings of IPAC study, which had $13 \%$ major events at the end of one year. ${ }^{4}$

Though PPCM resembles dilated cardiomyopathy (DCM) clinically LV may not always be dilated. The ejection fraction is nearly always reduced below $45 \%$. This study found a mean ejection fraction of $26.82 \pm 8.38(15-45 \%)$ similar to a study $(28 \pm 9.9 \%)$ in USA. ${ }^{7}$ All patients who died had LVEF less than $30 \%$ at baseline. LVEF $>30 \%$ was not associated with good $\mathrm{LV}$ recovery at 3 months (P value 0.91 ). This finding is in contrary to the finding of IPAC study. ${ }^{4}$

Early recovery in patients with PPCM is significantly related to the degree of myocardial insult at the time of diagnosis. Recovery of LV function was more in $(54.5 \%)$ if the baseline LVEDD was less than $60 \mathrm{~mm}$ but this value was not statistically significant to correlate with the better outcome $(\mathrm{P}=0.15)$.

Although the disease has been reported in women between the ages of 16 and 44 years, the mean age of women with PPCM in the United States has ranged from 27 to 33 years. ${ }^{1,8}$ In this study, the mean age was found to be 27.6 years, which is similar to these studies. Age Less than 25 or more than 25 years did not correlate with the myocardial recovery.

Multiparty has been described as one of the predisposing factors in some studies from Pakistan $(3.66 \pm 1.5$ and $3.66 \pm 1.41$, respectively $)^{9,10}$ but majority of the women in this study were primigravida $(64 \%)$ with mean parity of $1.68 \pm 0.56$.

PPCM can present both before and after delivery. In this study majority of women $(83.4 \%)$ became symptomatic in postpartum period. The result is similar to other previous studies ( $71 \%$ in USA, and $68.8 \%$ in Pakistan). ${ }^{7,11}$

Small number of the study population was a major limitation of the study. Patients were enrolled only if they were admitted with heart failure in hospital, thus the study doesn't find out the outcome of less severe disease or if the therapy is initiated early in the course.

\section{Conclusion:}

This study demonstrates that survival outcome is better even in the patients with severe acute PPCM with early diagnosis and proper management of heart failure.

\section{References:}

1. Elkayam U.Clinical Characteristics of Peripartum Cardiomyopathy in the United States Diagnosis, Prognosis, and Management. J Am CollCardiol 2011;58:659-70.

2. Pearson GD, Veillie JC, Rahimtoola $\mathrm{S}$ et al. Peripartum CardiomyopathyNational Heart, Lung, and Blood Institute and Office of Rare Diseases (National Institutes of Health) Workshop Recommendations and review.JAMA 2000; 283(9): 1183-1188.

3. Goland S, Modi K, BitarF,et al. Clinical profile and predictors of complication in peripartum cardiomyopathy. J cardiac Fail 2009; 15:645-50.

4. Dennis M, McNamara, Elkayam U et al. Clinical Outcomes for Peripartum Cardiomyopathy in North America. J Am col cardiol 2015; 66:905-14.

5. Yancy CW, Jessup M, Bozkurt B et al.2013 ACCF/AHA guideline for the management of heat failure: a report of the American college of Cardiology Foundation/ American Heart association Task force on Practice Guidelines. J Am CollCardiol 2013,62e147-239.

6. Authors/Task force members, McMurray JJ, Adamapoulos S, et al. ESC guidelines for the diagnosis and treatment of acute and chronic heart failure 2012. Eur Heart J 2012; 33:1787-847.

7. Pillarisetti J, Kondur A, Alani A, et al. Peripartum cardiomyopathy: Predictors of recovery and current state of implantable cardioverter-defibrillator use. J Am CollCardiol2014;63:2831-9.

8. Harper MA, Meyer RE, Berg CJ. Peripartum cardiomyopathy: Population-based birth prevalence and 7-year mortality. Obstet and Gynecol2012; 120:1013-9.

9. Hasan JA, Qureshi A, Ramejo BB, et al. Peripartum cardiomyopathy characteristics and outcome in a tertiary care hospital. J Pak Med Assoc2010; 60:377-80.

10. Shah I ST, Faheem M,Kamran A. et al. Peripartum cardiomyopathy: Risk factors, hospital course and prognosis; experience at lady reading hospital peshawar. Pak Heart J 2012; 45:108-15.

11. Laghari AH, Khan AH, Kazmi KA. Peripartum cardiomyopathy: Ten year experience at a tertiary care hospital in Pakistan. BMC Res Notes 2013; 6:495.
Cite this article as: Rajesh Nepal, Madhav Bista, Sita Ghimire. Early outcome of acute peripartum cardiomyopathy in eastern part of Nepal. Nepalese Heart Journal 2017; 14(1): $13-15$ 